\title{
On the Combination Between Information Technology and the Sports Industry
}

\author{
Lan-hui Wu \\ Mianyang Normal University, The Institute for Health Education \\ Sichuan Mianyang 621000
}

\begin{abstract}
In the network information technology as the role of the media, sports fitness and entertainment industry in social demand will be greater, have a more broad market prospects, at the same time it has the organic composition of capital is low, less investment, quick returns characteristics, is more industry absorbing labor. In addition, because of the information technology on the traditional sporting goods manufacturing industry to transform, can not only meet the public consumption, and can obtain more profit, is to promote the development of sports industry in China power. Therefore, in order to promote the sports industry departments coordinated, balanced development, we should be in support of information technology gives priority to the development of the industry.
\end{abstract}

Key words-information technology; sports industry; combination

\section{INTRODUCTION}

With the development of information technology, whose applications in all walks of life such as bamboo shoots after a spring rain as the craze. Information technology and sports fields combined, has a long history. From the 1964 Tokyo Olympic Games, Barcelona in 1992, 1996, 2000 Sydney to Atlanta in 2004 Athens Olympic Games, all left the information technology.Nowadays, along with the information technology maturity, in sports and like a raging fire development, forming a new digital sports industry.Can be said that the information technology's application in sports field, initiated the new phase of growth of the national economy.

\section{INFORMATION TECHNOLOGY CHARACTERISTIC}

\section{A. Highly strategic}

Information technology to a country's politics, economy, military affairs as well as in the world the position in pattern to produce a role can not be ignored, therefore, the information technology has already become measure a country comprehensive national landmark. In twenty-first Century the face of international competition, each country has realized, who owns the advanced information technology, who can be in competition remain invincible.

\section{B. Highly creative}

Information technology innovation is not only the original technology on the road to simple accumulation, but the establishment of modern science and technology on the latest achievements and important inventions of innovation. Such as, semiconductor, microelectronics, computer, laser show highly innovative information technology. A significant innovation and the wider use of products have the close relation, which serves as the first productivity, created enormous wealth for the society and economic benefits, but also to promote the science and technology, the production, the adjustment of industrial structure has made immeasurable dedication.

\section{Highly permeable}

Information technology as an integrated, interdisciplinary and strong technical field, so that it can widely infiltrated into various traditional sectors to undertake technical reformation, improve the upgrading of products, reduce labor intensity, saving energy and raw materials, improve productivity. According to the United States General Company of the company 160 enterprises indicated that, after using CAD/CAM brings profit, $56 \%$ is the result of using information technology to improve labor productivity and obtain.

\section{The high input resistance}

Information technology is the knowledge, talent, capital is concentrated model the emerging technologies group, for information technology input will be significantly higher than the general traditional technology. Information technology research and development, need much capital investment, this is because information technology is knowledge concentrated model and talent concentrated model decision.

\section{INFORMATION TECHNOLOGY PROMOTING THE DEVELOPMENT OF THE SPORTS INDUSTRY MECHANISM ANALYSIS}

\section{A. Drive a batch of burgeoning high profit industry}

Information technology 's greatness lies not only in that it can optimize the development of other industry, more important is to be able to drive a large number of new industries, such as the sports industry, sports communication industry and sports industry. The emerging electronic athletics industry development status of electronic games, information technology and sports extensive combination. Such as sports FIFA NBA football, basketball; shooting FPS, such as delta force, Counter-Strike, are recognized by the international. Electronic sports industry is a highly profitable industry, according to the United States of America 's International Institute recently pointed out, in 2006 the global game industry will be $16.5 \%$ growth, 2005 North American video output value reached $\$ 18500000000$, with approximately 48000000 people tend to network computer game, the United States will become the largest online gaming market. Korea 
catch up from behind, in the government give aid to energetically below, already ranked among the world's top game kingdom, game become Korea national skill, the game industry has become pillar industries of this country. China electronic athletics industry interaction platform launched in Beijing on November 18, 2003 people congress hall is held ceremoniously. The All-China Sports Federation, Chinese Olympic Committee and CITIC Pacific Limited announced here, three party to vigorously promote the information application in sports, together to create China Digital Sports Interactive platform. Electronic athletic sports has been as the State Sport General Administration officially launched in ninety-ninth sports.

\section{B. Optimization of industrial structure}

Reasonable structure of the sports industry will make sports industry departments to maintain a balance between development, can allow for effective use of manpower, material resources, financial resources and other resources. Therefore, in China's sports industry developing plan, first of all, to establish a reasonable structure of sports industry. In the network information technology as the role of the media, sports fitness and entertainment industry in social demand will be greater, have a more broad market prospects, at the same time it has the organic composition of capital is low, less investment, quick returns characteristics, is more industry absorbing labor. In addition, because of the information technology on the traditional sporting goods manufacturing industry to transform, can not only meet the public consumption, and can obtain more profit, is to promote the development of sports industry in China power. Therefore, in order to promote the sports industry departments coordinated, balanced development, we must in the support of information technology gives priority to the development of the industry.

\section{Changes in people's concept of sports consumption}

With national attention and the improvement of living level, people pay more and more attention to sports consumption. Television, radio, information technology, the media is more people will be attracted to the sports consumption in. People can remain within doors concept around the world to see the exciting sports events. According to statistics, the United States 3/4 per week at least by a televised sports events, and Italy almost all television broadcasting Serie A with lots of time. Losangeles Olympic Games television audience amounts to 20000000000 person-time, the 1996 Atlanta Olympic Games only television costs exceeded $\$ 700000000$, and our country is annual by television sports audience of more than 1600000000 people. As a result of information technology and other news media to carry out various forms of publicity and education, promote people to change the understanding of sports, sports not only become the people living habits, and has become the important component of consumer expenditure, to spend money to buy health, buy to enjoy and get spiritual pleasure sports for a considerable crowd recognition and accept, objectively enlarges the market of sports consumption. Sports consumption from propaganda recreational and participatory activities, sporting goods, sports lottery, sports intangible assets consumption, become new economic growth point of China in twenty-first Century.

\section{The change of sport products marketing tools}

With the economic integration and the establishment of market economy system, all walks of life between the competition is more intense, to open product market, establish a good corporate image, make every attempt to win consumers, exchange the biggest economic benefits, enterprises will actively advertising. But the traditional advertisement effect is often difficult problems, through the network of information technology, enterprises can quickly and accurately understand market trends and almost every customer needs. Similarly, the consumer can be feedback to the sports enterprises, enterprises and provide them different sports product combination, make sports products supply to "tailor " the direction of development. It not only improves the producers and consumers of the level of cooperation between, improve product quality, but also greatly reduces the cost of sales of sports industry. The rapid development of computer technology raises money in the form of change: from tangible assets to intangible assets, a string of numbers, symbols instead of money, greatly accelerate the commodity trading and money transmission speed. The traditional commodity circulation intermediaries and a counter sales will be network technique to compress the living space, online shopping, online payment is the convenience of network system.

\section{E. The change of production mode of operation of sports industry}

With the intense competition, the single enterprise has been unable to meet customer demand for personalized, need between the enterprise and enterprise alliance, play to their own advantage, form dimensions benefit, this is a form of virtual enterprise. The virtual enterprise is will not belong to the person of the enterprise, equipment and other resources combined, connected through the Internet to work together, to provide services and products to make concerted reaction, in order to achieve certain carefully defined target organization form, which is actually the coordination theory and computer network technology in the operation of enterprises on the embodiment and application. The famous international sports clothing and equipment brand NIKE company in 20 years ago in the success of the company, and do not have their own production lines, the company only provide product design, request and authorize the trademark, to the product in the form of outsourcing production, production after the company acquired and marketing. Virtual enterprise operation is computer network technology in enterprise's concrete application, only in the computer network of enterprises can quickly respond to the market, can make use of shared information interaction work together.

\section{F. Strengthen the sports industry management}

Along with the network information technology into the field of sports, international sports events are relatively large have adopted computer network management. Large scale sports events distribution in many venues, involve personnel information registration and change, staff information accuracy is particularly important. Through computer data technology, can be stored in the central database information focus. Information changes can be centrally managed or authorized in various venues distributed, venues database 
through the network and the central data base data communication and synchronization, so as to ensure the accuracy and consistency of information personnel. In the sporting goods manufacturing industry, also introduced a variety of management information system, enhances the management efficiency and working level.

\section{THE USE OF INFORMATION TECHNOLOGY, PROMOTING THE DEVELOPMENT OF THE SPORTS INDUSTRY THE WAY}

A. The use of information technology, to enhance the people 's sports consciousness along with the people living standard enhancement

We must increase the physical function of the propagandist strength, arouse people to actively participate in sports consciousness, make it possible for people to form a correct concept of sports consumption, and consciously participate in sports physical fitness and recreational activities, further tap the sports consumption market potential, to become a bright spot in the national economic growth.

B. As a result of the information technology of high input, must rely on government support

Sports industry in many developed countries to become the pillar industry of national economy, but the present situation in our country, sports industry and education, cultural comparison, the apparent lack of government support. Our whole physical capital investment of fiscal expenditure in China accounted for only $0.4 \%$. than even the economy is not developed in India, India on the sports investment accounts for the national fiscal expenditure 1\%. National Sports Training Council annual funding gap amounts to about 10000000 yuan, so sports funds. According to the data, our country existing stadiums per capita is only $0.55 \mathrm{~m} 2$, and American per capita $14 \mathrm{~m} 2$. This shows that China's sports facilities, site of shortage, unable to meet the broad masses of the people increasing fitness entertainment needs.

C. The use of information technology, improve the sports industry production and marketing and innovation ability

Through the information technology to the traditional sports industry transformation, and continuously improve the sports industry product quality, and actively develop quality and cheap sports products. Through market supply demand relations and mass media to promote the sports business and product sales, to meet consumer demand for mass sports service, sports competition performance of various levels of demand, promote the sustainable, healthy development of the sports industry. In the knowledge economy society, the people of the sports products and sports consumption patterns will present many new and higher requirements, in addition, a new way of life such as adventure tourism, extreme sports and other projects in the future, there are broad prospects, in this case, the enterprise must use the information technology, continuous innovation, increase knowledge content, in order to adapt to market demand.

D. The use of information technology, strengthen the cooperation between sports industry

The present stage of our country 's sports industry small scale of operation, operating a variety of dispersive, competition ability is not strong, not with the well-known international brands to compete, but only through the use of information technology, strengthen cooperation between enterprises, the advantage is complementary, powerful powerful combination, common to create their own brands, establish their own brands can be effectively to solve the.

\section{CONCLUSIONS}

Mankind has entered the information age, computer and network as the core of modern technology continuous development, is becoming more and more profoundly changing our way of life and production, working way and way of studying. The modernization of education increasingly rapid pace, modern information technology has entered the school, entered the classroom. Only a clear modern information technology teaching and traditional sports teaching, modern information technology teaching ability in physical education played a very good role. Modern information technique teaching can not be used as sports teaching is the main teaching means, it is only an auxiliary teaching tool, is a kind of means, a form of teaching, plays the decision role or the teaching content and teaching method. We only use modern information technology teaching advantage, face the traditional teaching methods of practical value, can be properly, the correct use of it, thus truly entered the modern era of information technology teaching.

\section{REFERENCE}

[1] Hao Wunan, Su Qiaoru. On sports industrialization and sports legal construction [J]. Journal of physical education, 1999, (5): 22-25.

[2] Xiao Peixiong, Lu Shuting, beam out, such as.21 century information industry and sports industry [J]. Guangzhou Sports University, 2002, (3): 68-70.

[3] Liu Xijia, Zhou Jiang, Zhao Shilu. The modern scientific technology and sports industry development [J]. market modernization, 2007, (5): 45-46.

[4] Deng Yu. Information technology to promote sports development behind the [N]. China sports daily, 2009-09-02.

[5] Zhao Xi sports market diversification expansion policy started [J]. consumption daily, 2010-03-29. 